\title{
Production and use of triploid zebrafish for surrogate reproduction
}

3 Roman Franěk*, Tomáš Tichopád, Michaela Fučíková, Christoph Steinbach, Martin Pšenička

$4 \quad$ RF franek@frov.jcu.cz, $\quad$ TT tichopad@frov.jcu.cz, $\quad$ CS $\underline{\text { steinbach@ frov.jcu.cz, }} \quad$ MP 5 psenicka@frov.jcu.cz

6 University of South Bohemia in České Budějovice, Faculty of Fisheries and Protection of Waters,

7 South Bohemian Research Center of Aquaculture and Biodiversity of Hydrocenoses, Zátiší 728/II,

838925 Vodňany, Czech Republic;

*Corresponding author: Roman Franěk, Zátiší 728/II, 38925 Vodňany, Czech Republic

11 franek@frov.jcu.cz

12 Abstract:

13 We report for first time comparison of two approaches for zebrafish triploid production using cold 14 shock and heat shock treatment. Subsequently, produced triploid zebrafish were used as a recipients 15 for intraperitoneal transplantation of ovarian and testicular cells originating from vas:EGFP strain in 16 order to verify their suitability for surrogate reproduction. Heat shock treatment was far more 17 effective evaluated as success rate of triploid production and viability in comparison to cold shock. 18 Triploids were produced with up to $100 \%$ efficiency in particular females. As expected, all triploids 19 were males. Subsequently, germ cells transplantation revealed that triploids are suitable surrogate 20 hosts. Production of donor-derived sperm was achieved in $23 \%$ and $16 \%$ of triploids transplanted 21 by testicular and ovarian cells, respectively. Success of the transplantation was confirmed by 22 positive GFP signal detected in gonads of dissected fish and stripped sperm. Germline transmission 23 was confirmed by fertilization tests followed by PCR analysis of embryos. Reproductive success of 24 germline chimera triploids evaluated as fertilization rate and progeny development was comparable 25 to control groups.

26 Keywords: zebrafish, chromosome manipulation, triploid, germ cell transplantation, surrogate 27 reproduction 


\section{Introduction:}

30 Surrogate reproduction in fish via intraperitoneal germ cell transplantation is a promising 31 technology for aquaculture as well preservation of endangered species when recipient species with 32 more favorable characteristics can be used [1]. So far germ cell technologies are being applied in 33 wide range of fish species such as, salmonids [2,3], cyprinids [4,5], Nile tilapia [6-8], medaka [9], sturgeons [10-12] or several marine fish species [13,14]. One from the main prerequisites for successful surrogate propagation is the host's sterility ensuring no contamination of donor-derived gametes during reproduction [2] and very likely lower competition for space in gonads between endogenous germ cells and introduced exogenous germ cells resulting in higher production of donor-derived gametes.

Importance of zebrafish for surrogate reproduction is in its biological and reproductive characteristics as fast maturation or availability of transgenic lines could enable to study unknown factors affecting the success of germ cell transplantation. Moreover, zebrafish can serve as a valuable model for sterility research since several distinct methods are available for sterility induction nowadays Early ablation of primordial germ cells (PGCs) can be achieved using gene knock out approaches such as Zinc Finger Nucleases against dead end (dnd) gene [15], or gene knock down with dnd antisense morpholino oligonucleotide [16,17]. Both methods require microinjection into embryos, thus an alternative approach using immersion in vivo morpholino against $d n d$ can be more convenient in case of large scale application (Wong and Zohar, 2015). Sterility was achieved via PGCs depletion in transgenic fish with artificially induced nitroreductase expression in PGCs exclusively using immersion into metronidazole enzyme which was converted into toxic metabolites and only PGCs targeted toxicity was achieved [19]. Similarly, PGCs migration was disrupted in transgenic fish which had SDF1 expression controlled by a heat shock protein. Regular event of PGCs migration is beside other mechanism guided by SDF1 gradient towards the genital ridge, however, heat treatment caused throughout expression of SDF1 resulting in migration failure and production of sterile fish [20]. A cytostatic drug such as busulfan was used successfully in combination with thermal treatment, however, this method was developed only for adult fishes, because intraperitoneal administration is necessary [21]. All abovementioned methods for sterility achievement can be regarded as relatively demanding from point of time, knowledge and equipment. Thus a simple method for sterile fish generation such as production of infertile Danio hybrids by crossing zebrafish and pearl danio is convenient from point of time and possibility to produce host by simple fertilization without additional treatment [22]. Similarly, triploid fish can be produced as hosts in surrogate reproduction technology [2,9,14]. Moreover, triploids or 
sterile hybrids can still be more favorable way for surrogate host production in fish species without mapped genomes or at least genes of interest not enabling use of targeted transgenic or gene silencing approaches [23], or when large scale production of sterile recipients is needed or microinjection delivery of compounds inducting sterility into the eggs is difficult due to sturdy chorion as it is known for marine fish species [24,25].

Three sets of chromosomes in artificially induced triploids cannot proceed through meiosis and gamete maturation regularly, resulting in gametogenesis arrest or aneuploid gametes production further incompatible with the proper embryonic development [26]. Triploids can be induced by pressure or temperature treatment or electric shock resulting in inhibition of second polar body extrusion. However, all abovementioned physical treatments, require equipment such as pressure chamber and thermostat respectively [27-32]. Therefore, an alternative technique using cold shock could be convenient from point of the material equipment, might has less deleterious effect on the survival but with the same efficiency of triploid induction rate as the heat shock treatment.

Method for triploid zebrafish production using heat shock treatment was published already [33]. However, we did not succeed satisfactorily using the abovementioned heat shock protocol in our laboratory. Therefore we revised the procedure for heat shock treatment and compared it with cold shock to identify an optimal condition for triploid zebrafish production with respect to achieve the highest survival and produce triploid fish. Suitability of triploid fish as surrogate recipients was tested by intraperitoneal transplantation by testicular and ovarian cells from vas:EGFP strain and subsequent production of donor-derived gametes with fertility tests confirmed by fluorescent microscopy and DNA analysis. 


\section{Material and methods}

The study was conducted at the Faculty of Fisheries and Protection of Waters (FFPW), University of South Bohemia in České Budějovice, Vodňany, Czech Republic. The facility has the competence to perform experiments on animals (Act no. 246/1992 Coll., ref. number 16OZ19179/2016-17214). The methodological protocol of the current study was approved by the expert committee of the Institutional Animal Care and Use Committee of the FFPW according to the law on the protection of animals against cruelty (reference number: MSMT-6406/119/2). The study did not involve endangered or protected species. Martin Pšenička owns the certificate (CZ 00673) giving capacity to conduct and manage experiments involving animals according to section 15d paragraph 3 of Act no. 246/1992 Coll.

\subsection{Fish and gamete collection}

Mature zebrafish spawners from AB line were purchased from European Zebrafish Resource Center (Germany), vas:EGFP line was purchased from University of Liège, Belgium, were maintained in a zebrafish housing system (ZebTEC Active Blue) at $28{ }^{\circ} \mathrm{C}, 14 \mathrm{~L}: 10 \mathrm{D}$ photoperiod, feeding two times with Tetramin flakes and once with Artemia nauplii. Fish were set into the spawning chambers afternoon before the spawning (one male and one female) and separated with a barrier. On the light onset of the next day, the barrier was removed and fish were observed for oviposition. Selected fish were immediately transferred into the laboratory. Gametes for in vitro fertilization were obtained after anesthesia in $0.05 \%$ tricaine solution (Ethyl 3-aminobenzoate methanesulfonate). Sperm from at least 5 males was pooled together in $50 \mu \mathrm{l}$ of Kurokura 180 solution [34], eggs were collected from each female separately and fertilized promptly. Fertilized eggs were divided into control and treated groups and were cultured at $28.5^{\circ} \mathrm{C}$ constantly.

\subsection{Triploid induction and rearing}

Cold shock (CS) treatment for the given time was conducted with fertilized eggs in a plastic strainer placed in a Styrofoam box with 2 L of ice chilled water. Heat shock (HS) treatment was conducted in a plastic strainer placed in a $5 \mathrm{~L}$ recirculated water bath with thermostat under varying conditions. Parameters used in all CS and HS trials are summarized in Table 1.

The remainder of the intact fertilized eggs from each female was kept as a non-treated control. Females $(\mathrm{n}=7)$ producing eggs with fertilization rate in control below $65 \%$ were regarded as having bad quality and were excluded from results and replaced by new females. Swim-up larvae were fed by paramecium for one week, later on with Artemia nauplii ad libitum and held until the 
$\lfloor 17$ first month in an incubator in plastic boxes. Fish were then transferred into a zebrafish housing L18 system and were kept until reaching maturity. Five females with separately fertilized eggs were $\lfloor 19$ used as replicates. Eggs from each female were divided into approximately same portions into 3(4) groups according to tested variables in performed treatment and one untreated control constantly held at $28.5^{\circ} \mathrm{C}$. Survival was recorder as a percentage of living embryos from number of fertilized eggs

\begin{tabular}{cccc} 
Treatment & Temperature & Duration time & Initiation time \\
\hline \multicolumn{4}{c}{ Cold shock } \\
\hline CS temperature & $3,6,9^{\circ} \mathrm{C}$ & $5 \mathrm{~min}$ & $1 \mathrm{mpf}$ \\
CS duration & $6{ }^{\circ} \mathrm{C}$ & $5,10,15 \mathrm{~min}$ & $1 \mathrm{mpf}$ \\
CS initiation time & $6{ }^{\circ} \mathrm{C}$ & $5 \mathrm{~min}$ & $0.5,1 \mathrm{mpf}$ \\
\hline \multicolumn{4}{c}{ Heat shock } \\
HS temperature & $41,41.4,42{ }^{\circ} \mathrm{C}$ & $2 \mathrm{~min}$ & $2 \mathrm{mpf}$ \\
HS duration & $41.4{ }^{\circ} \mathrm{C}$ & $1,2,3,4 \mathrm{~min}$ & $2 \mathrm{mpf}$ \\
HS initiation & $41.4^{\circ} \mathrm{C}$ & $2 \mathrm{~min}$ & $1,2 \mathrm{mpf}$ \\
\hline
\end{tabular}

Table 1 Variables tested during optimization of triploid zebrafish production.

mpf - minute post fertilization

\subsection{Flow cytometry}

Only larvae after swim-up stage were used for triploidy confirmation in trials in order to obtain results representing only viable triploids. Whole larvae (euthanized by tricaine overdosing) or later on fin clips were processed using a kit for nuclei staining CyStain UV Precise T (Sysmex Partec $\mathrm{GmbH}$, Germany) according to the manufacturer's protocol. The relative DNA content was determined using a CyFlow Ploidy Analyzer (Sysmex Partec GmbH, Germany) against samples from diploid control groups. Ten larvae were analyzed from each female in each treatment and group.

\subsection{Transplantation}

Male and female germ cell donors from vas:EGFP line were euthanized by tricaine overdosing, decapitated, the body was washed with $70 \%$ ethanol. Testis from two donors were excised aseptically. Each testis was cut into 4-6 fragments and washed several times in phosphate buffered saline (PBS) in order to remove leaking sperm. Medium for testicular tissue digestion contained $0.1 \%$ trypsin, $0.05 \%$ DNAse dissolved in PBS. Fragments were collected by a pipette and transferred into $2 \mathrm{~mL}$ tube with $1 \mathrm{~mL}$ of digestion medium and were further minced with scissors and placed on a laboratory shaker for $50 \mathrm{~min}$. Digestion was terminated by addition of $1 \mathrm{~mL} \mathrm{L-15}$ 
and $10 \%$ FBS (v:v). The suspension was filtrated through a $30 \mu$ m nylon filter (CellTrics ${ }^{\circledR}$ Sysmex, Germany) and centrifuged at $0.3 \mathrm{~g}$ for $10 \mathrm{~min}$. The supernatant was removed and the pellet was resuspended in $40 \mu \mathrm{L}$-15 with $10 \%$ FBS. Female germ cells were collected from juvenile donors ( 2 months, $\mathrm{n}=5$ per one transplantation trial) and digested as described for testicular cells. After centrifugation, ovarian cells suspension was washed and filtrated two times to remove excess of debris.

Triploid recipients produced by optimized HS procedure were anaesthetized at $7 \mathrm{dpt}$ in $0.05 \%$ tricaine and placed on petri dish coated with $1 \%$ agar. Testicular and ovarian cell suspension was loaded into the glass capillary attached to MN-153 micromanipulator (Narishige) and FemtoJet@ 4x injector (Eppendorf). Triploid recipients were injected by approximately 3000-5000 of testicular cells (TC group) or 500 ovarian cells (OC group) per individual. Each transplantation trial for TC and OC groups consisted of 30 transplanted fish when triploid recipients were originating from same batch in both groups. The remainder of non-injected triploids and non HS treated diploids was kept as a control and no operation was conducted on them. Transplanted fish were left to recover in dechlorinated tap water. Survival and colonization rate of transplanted cells was monitored until adulthood. Fish were observed and photographed under a fluorescent stereomicroscope (Leica M205 FA) with fluorescent filters DAPI/FITC/TRITC (order no 10450614) or GFP (order no

\subsection{Production of donor-derived gametes}

163 All adult surviving fish were screened for positive GFP signal in their testis. GFP positive germline

164 chimeras were set into spawning chamber afternoon (two or three males and separated one female).

l65 Males were following morning anaesthetized and sperm was collected and observed under an

166 inverted fluorescent microscope to detect positive GFP signal in sperm. All fish producing GFP

167 positive sperm from each transplantation trial were pooled together into one TC and one OC group 168 and left to recover for 4 weeks.

169 Randomly selected fish from pooled TC and OC group (10 fish per group) were propagated by semi-natural mating and in vitro fertilization. Semi-natural mating was conducted in spawning

171 chambers when one germline chimera triploid male and two AB females in reproductive condition

172 were set together in the afternoon and separated with a barrier. Next day at the onset of light, a

173 barrier was removed and fish were allowed to spawn for three hours. Spawned eggs were collected

174 and the survival rate was monitored. Swim up larvae from each group were pooled and 10 175 individuals were selected randomly and used for PCR analysis to verify the efficiency of germline 
transmission. Used germline chimeras in semi-natural mating were separated and were not used for following in vitro fertilization. Procedure for in vitro fertilization was the same as described for $\mathrm{AB}$ line (2.1). Sperm collected from each chimeric male was stored separately in immobilizing solution. Eggs were stripped from $\mathrm{AB}$ females $(\mathrm{n}=4)$, gently mixed, divided into approximately same portions and fertilized with sperm from chimeric triploid males individually. Control group for semi-natural and in vitro fertilization consisted $\mathrm{AB}$ females and vas:EGFP males. Survival of produced embryos was monitored. Offspring from each group were pooled together and 10 randomly selected larvae were used for PCR analysis. DNA was extracted from larvae by PureLink $^{\mathrm{TM}}$ Genomic DNA Mini Kit (Invitrogen $^{\mathrm{TM}}$ ). GFP forward primer ACGTAAACGGCCACAAGTTC, reverse primer AAGTCGTGCTGCTTCATGTG. Primers were tested for specifity. The reaction mixture for PCR contained $1 \mu 1$ template cDNA, $0.5 \mu 1$ forward and $0.5 \mu 1$ reverse primer, $5 \mu 1$ PPP Master Mix (Top-Bio) and $3 \mu 1$ PCR H2O (Top-Bio). Reaction conditions were 30 cycles of $94{ }^{\circ} \mathrm{C}$ for $30 \mathrm{~s}, 58{ }^{\circ} \mathrm{C}$ for $30 \mathrm{~s}$ and $72{ }^{\circ} \mathrm{C}$ for $30 \mathrm{~s}$. Products were analyzed on gel electrophoresis on $2 \%$ agarose gel on a UV illuminator.

\subsection{Histology analysis}

Euthanized zebrafish triploids and diploid controls were fixed overnight in the Bouin's fixative. Samples were immersed in $70 \%$ ethanol, dehydrated and cleared in an ethanol-xylene series, embedded into paraffin blocks and cut into $4 \mu \mathrm{m}$ thick sections using a rotary microtome (Leica RM2235). Paraffin slides were stained with hematoxylin and eosin by using a staining machine (Tissue-Tek DRS 2000) according to standard procedures. Histological sections were photographed and evaluated using a microscope with mounted camera (Nikon Eclipse $\mathrm{C} i$ ).

\subsection{Statistical analysis}

Survival of embryos was analyzed by logistic regression with mixed effects where the treatment was set as fixed effect while females were set as random effect with different intercepts (as mentioned above, eggs in each groups were obtained from five females). Post hoc Tukey's test was performed to find out significant differences among groups of different treatment. The effect of treatment on a number of triploids was analyzed by Friedman test where individual females were set as blocks. Differences among groups were analyzed by Post-hoc Conover test with BenjaminiHochberg correction [35]. All analysis were performed in R software (3.5.2).

\section{Results}




\subsection{Production of triploid recipients for surrogate reproduction}

210 The testing of CS revealed that exposition in $6{ }^{\circ} \mathrm{C}$ water bath resulted in significantly higher triploid

211 production and survival in comparison to $\mathrm{CS}$ at $3^{\circ} \mathrm{C}$. Few triploids were also produced at $3{ }^{\circ} \mathrm{C} \mathrm{CS}$,

212 but lower temperature was more detrimental to early embryonic development when even swim-up

213 embryos exhibited malformations (Supplementary figure 1). Cold shock conducted at $9{ }^{\circ} \mathrm{C}$ had the

214 lower effectiveness for triploid induction. Testing of prolonged CS duration yielded comparable

215 fraction of detected triploids in all tested durations, however, survival rate was more favorable in 5

216 and $10 \mathrm{~min}$ lasting CS treatment. Optimized CS temperature $\left(6^{\circ} \mathrm{C}\right)$ and duration $(5 \mathrm{~min})$ were used

217 further to test different initiation times after fertilization. Yield of triploid fish was improved

218 significantly when CS was initiated at 30 seconds post fertilization (spf) (Figure 1A-C).

219 Triploid induction by HS treatment tested different temperatures and shock duration during the first 220 trial. HS treatment at $42{ }^{\circ} \mathrm{C}$ was lethal for all embryos (data not shown) and viable triploids were 221 produced only at 41 and $41.4^{\circ} \mathrm{C}$. Viability and triploid yield was slightly in favor of $\mathrm{HS}$ at $41.4^{\circ} \mathrm{C}$, 222 and thus it was used in the second HS trial assessing different HS durations. Fraction of detected 223 triploids in HS treated embryos was significantly higher at HS lasting 1 and 2 min, and further HS 224 prolongation resulted in significantly decreased survival rate only. Last HS trial tested different 225 initiation time for $\mathrm{HS}$ treatment at $41.4{ }^{\circ} \mathrm{C}$ lasting $2 \mathrm{~min}$. Treatment initiated $2 \mathrm{mpf}$ (minutes post 226 fertilization) yielded significant higher survival as well as triploid induction rate in comparison to $2271 \mathrm{mpf}$ (Figure $1 \mathrm{D}-\mathrm{F}$ ), moreover, embryos treated at $1 \mathrm{mpf}$ had less expanded chorion 228 (Supplementary figure 2) and most of them did not hatched even when embryos appeared to be 229 developed normally. Therefore, treatment at $41.4{ }^{\circ} \mathrm{C}$ initiated 2 mpf and lasting 2 min was 230 identified as optimal protocol for triploid induction and was used to produce recipients for 231 germ cell transplantation in following experiment.

Figure 2

\subsection{Germline chimera generation and reproduction}

236 Despite of relatively invasive transplantation and sequentially presence of exogenous cells, the survival rate was similar among transplanted triploids, non-transplanted triploids and control diploids (Table 2). Transplanted testicular and ovarian cells from vas:EGFP donors (Figure 2) into triploid recipient showed strong signal after transplantation (Figure 3a). At 1wpt genital ridge of 
transplanted fish showed various patterns of germ cell colonization, large number of transplanted cells surrounded whole glass bladder (Figure 3 B); 5-20 cells located in the genital ridge close to the posterior part of the gas bladder; few individual cells located alongside the genital ridge. All patterns of colonization were represented in approximately same ratio. Transplanted ovarian cells were mostly found as a few or individual cells alongside the genital ridge, probably due to the lower number of transplanted cells. More than half of the positive germline chimeras receiving testicular cells showed the colonization bilaterally in the genital ridges. Noticeable proliferation of transplanted cells started at 7-12 dpt in majority of positive germline chimeras. Observation of transplanted fish at 2-3 wpt showed GFP positive cells proliferating and forming clusters alongside the gas bladder (Figure $3 \mathrm{C}, \mathrm{E}$ ) or progression towards the anterior in case of cells originally colonizing posterior part of gas bladder. Observation of gonadal development was difficult due to deposits of fat cells surrounding gonads (Figure 3 E, E'). Typical patterns of vas:EGFP cells development in triploid recipients are shown in Figure 3. Fish were screened at 10 weeks post

253 fertilization (wpf) for presence of GFP signal in gonads (Figure 4) and finclips of positive germline 254 chimeras were taken for flow cytometry examination and triploidy of all positive chimeras was confirmed. All chimeras developed phenotypically in males regardless of origin of transplanted cells (testicular or ovarian). Colonization rate assessed by 10dpt was higher in TC groups in

\section{Figure 3}

260 Colonized part of the testis of dissected adults could be detected easily in bright filed according to 261 its white color with observable lobules while control triploid testis were almost transparent (Figure

262 4). Exogenous cells were localized unilaterally mostly when middle and/or posterior part of the 263 gonad was colonized with little extent towards anterior. Triploids developed phenotypic testis, with 264 visible spermatogonia clusters, spermatids (including spermatids apparently in zygotene and 265 pachytene stage) when only few spermatozoa were observed in the tubular lumens from non266 transplanted control. Testis from control diploid testis had tubular lumens filled with spermatozoa. 267 (Figure 5). Dissection showed positive GFP signal in triploid germline chimeras and in control 268 donor vas:EGFP strain, while no GFP signal was detected in control non-transplanted triploid and 269 normal control AB males.

\section{$270 \quad$ Figure 4}




\begin{tabular}{|c|c|c|c|c|c|c|c|c|c|c|c|c|c|}
\hline \multirow{2}{*}{\multicolumn{2}{|c|}{$\begin{array}{l}\text { Trial } \\
\text { Group }\end{array}$}} & \multicolumn{4}{|c|}{1.} & \multicolumn{4}{|c|}{ II. } & \multicolumn{4}{|c|}{ III. } \\
\hline & & TC & OC & $3 n C$ & $2 n C$ & TC & OC & $3 n C$ & $2 n C$ & TC & OC & $3 n C$ & $2 n C$ \\
\hline \multicolumn{2}{|c|}{ Transplanted } & 30 & 30 & 30 & 30 & 30 & 30 & 30 & 30 & 30 & 30 & 30 & 30 \\
\hline $24 \mathrm{hpt}$ & Survival & 29 & 28 & 29 & 30 & 28 & 29 & 30 & 30 & 29 & 29 & 30 & 30 \\
\hline \multirow{2}{*}{$1 \mathrm{wpt}$} & Survival total & 27 & 26 & 28 & 29 & 28 & 26 & 28 & 28 & 27 & 26 & 26 & 27 \\
\hline & GFP + & 22 & 18 & - & - & 15 & 16 & - & - & 24 & 15 & - & - \\
\hline \multirow{2}{*}{$2 w p t$} & $\begin{array}{c}\text { Survival } \\
\text { Total/GFP }\end{array}$ & $24 / 20$ & $22 / 17$ & $26 /-$ & $28 /-$ & $24 / 13$ & $23 / 14$ & $24 /-$ & $26 /-$ & $23 / 21$ & $21 / 11$ & $25 /-$ & $26 /-$ \\
\hline & GFP+ & 16 & 12 & - & - & 11 & 10 & - & - & 20 & 9 & - & - \\
\hline \multirow{2}{*}{$4 \mathrm{wpt}$} & $\begin{array}{c}\text { Survival } \\
\text { Total/GFP }\end{array}$ & $23 / 16$ & $20 / 11$ & $24 /-$ & $27 /-$ & $24 / 11$ & $20 / 9$ & $22 /-$ & $26 /-$ & $18 / 17$ & $19 / 8$ & $22 /-$ & $26 /-$ \\
\hline & GFP+ & 14 & 10 & - & - & 11 & 7 & - & - & 13 & 8 & - & - \\
\hline \multirow{2}{*}{ 10wpt } & $\begin{array}{c}\text { Survival } \\
\text { Total/GFP }\end{array}$ & $23 / 14^{*}$ & $19 / 10^{*}$ & $24 /-^{*}$ & $26 /$-* $^{*}$ & $24 / 11$ & $18 / 7$ & $22 /-$ & $26 /-$ & $18 / 13$ & $19 / 8$ & $22 /-$ & $23 /-$ \\
\hline & $\mathrm{GFP}+$ & 12 & 8 & - & - & 9 & 7 & - & - & 11 & 8 & - & - \\
\hline \multirow{3}{*}{ Adult } & $\begin{array}{c}\text { Survival } \\
\text { Total/GFP }\end{array}$ & $22 / 13$ & $18 / 9$ & $24 /-$ & $26 /-$ & $22 / 9$ & $18 / 7$ & $22 /-$ & $26 /-$ & $18 / 11$ & $19 / 8$ & $22 /-$ & $23 /-$ \\
\hline & GFP+ & 13 & 9 & - & - & 9 & 7 & - & - & 11 & 8 & - & - \\
\hline & GFP+ sperm & 11 & 7 & - & - & 7 & 5 & - & - & 9 & 7 & - & - \\
\hline
\end{tabular}

Table 2 Overall results from testicular and ovarian germ cell transplantation into triploid zebrafish recipients

Table 2 shows over results of germ cell transplantation into triploid recipients. Success of the transplantation was evaluated as a total numbers of surviving fish until adulthood with detected positive GFP signal (GFP+) in their gonads evaluated in vivo and successful collection of GFP

277 positive sperm from adult germline chimeras (GFP+ sperm). 3n C group represents remainder of the triploids from the batch used for 278 transplantation. 2n C group is part of embryos non-treated by HS. From 1 wpt until adult whole group was always screened for positive GFP 
280 Total/GFP represents number of fish surviving from previous screening counted before next screening. * Two GFP positive individuals from TC

281 and $\mathrm{OC}$ and from $3 \mathrm{n}$ and $2 \mathrm{n}$ control groups were sacrificed for gonad observation.


282 Majority of GFP positive triploid germline chimeras produced sperm, with GFP signal detected in 283 all collected samples (Table 2, Figure 6) and were capable to fertilize AB strain eggs during semi284 natural as well as in vitro fertilization. In overall, reproductive performance of triploid germline 285 chimeras was similar to diploid control males from vas:EGFP strain, however, both tests showed 286 that the control males from vas:EGFP always had the highest performance evaluated as 287 fertilization rate, survival $24 \mathrm{hpf}$ and swim up rate, while germline chimeras transplanted by 288 ovarian cell had the lowest survival rate (Table 2 and 3). Later PCR analysis confirmed 100\% 289 germline transmission, when GFP specific amplicon was detected (Table 3 and 4, Supplementary 290 figure 4).

\section{$291 \quad$ Figure 6}

292

\begin{tabular}{|c|c|c|c|c|c|c|}
\hline Group & Male & Eggs & Fertilization rate & Survival $24 \mathrm{hpf}$ & Swim up rate & GFP - PCR \\
\hline \multirow{6}{*}{ Testicular cells } & $\mathrm{m} 1$ & 39 & $32 / 82.1 \%$ & $25 / 64.1 \%$ & $21 / 53.8 \%$ & \multirow{6}{*}{$10 / 10$} \\
\hline & $\mathrm{m} 2$ & 66 & $60 / 90.9 \%$ & $55 / 83.3 \%$ & $49 / 74.2 \%$ & \\
\hline & m3 & 85 & $65 / 76.5 \%$ & $58 / 68.2 \%$ & $51 / 60 \%$ & \\
\hline & m4 & 52 & $46 / 88.5 \%$ & $40 / 76.9 \%$ & $34 / 65.4 \%$ & \\
\hline & $\mathrm{m} 5$ & 64 & $54 / 84.5 \%$ & $47 / 73.4 \%$ & $37 / 57.8 \%$ & \\
\hline & $\Sigma$ & 306 & $84.5 \pm 5 \%$ & $73.2 \pm 6.7 \%$ & $62.3 \pm 7.1 \%$ & \\
\hline \multirow{6}{*}{ Ovarian cells } & $\mathrm{m} 1$ & 56 & $46 / 82.1 \%$ & $46 / 82.1 \%$ & $42 / 75 \%$ & \multirow{6}{*}{$10 / 10$} \\
\hline & $\mathrm{m} 2$ & 41 & $35 / 85.4 \%$ & $31 / 75.6 \%$ & $18 / 43.9 \%$ & \\
\hline & m3 & 87 & $84 / 96.6 \%$ & $72 / 82.8$ & $59 / 67.8 \%$ & \\
\hline & $\mathrm{m} 4$ & 67 & $49 / 73.1 \%$ & $41 / 61.2 \%$ & $32 / 47.8 \%$ & \\
\hline & m5 & 43 & $31 / 72.1 \%$ & $25 / 58.1 \%$ & $15 / 34.9 \%$ & \\
\hline & $\Sigma$ & 294 & $81.9 \pm 8.9 \%$ & $72 \pm 10.4 \%$ & $53.9 \pm 15.1 \%$ & \\
\hline \multirow{6}{*}{ Control } & $\mathrm{m} 1$ & 68 & $56 / 82.4 \%$ & $51 / 75 \%$ & $50 / 73.5 \%$ & \multirow{6}{*}{$10 / 10$} \\
\hline & $\mathrm{m} 2$ & 36 & $32 / 88.9 \%$ & $29 / 80.6 \%$ & $25 / 69.4 \%$ & \\
\hline & $\mathrm{m} 3$ & 84 & $77 / 91.7 \%$ & $72 / 85.7 \%$ & $63 / 75 \%$ & \\
\hline & $\mathrm{m} 4$ & 32 & $29 / 90.6 \%$ & $22 / 68.8 \%$ & $17 / 53.1 \%$ & \\
\hline & m5 & 40 & $39 / 97.5 \%$ & $31 / 77.5 \%$ & $27 / 67.5 \%$ & \\
\hline & $\Sigma$ & 260 & $90.2 \pm 4.9 \%$ & $77.5 \pm 5.7 \%$ & $67.7 \pm 7.8 \%$ & \\
\hline
\end{tabular}

293 Table 3 In vitro fertilization test of triploid germline chimeras producing donor-derived sperm

294 Table 3 shows overall results of fertilization test when sperm collected from randomly chosen 295 germline chimera males was used to fertilize pooled eggs obtained by stripping from four males. 296 Fertilization rate, survival 24hpf and swim up rate is expressed in total numbers/\%, summarized 297 results from survival rates are expressed in \% as mean $\pm \mathrm{S}$ D. PCR - GFP shows results of 
298 detection of GFP specific amplicon in 10 randomly selected swim up larvae from pool in each 299 group

\begin{tabular}{|c|c|c|c|c|c|c|}
\hline Group & Male & Eggs & Fertilization rate & Survival $24 \mathrm{hpf}$ & Swim up rate & PCR - GFP \\
\hline \multirow{6}{*}{ Testicular cells } & $\mathrm{m} 1$ & 149 & $82 / 55 \%$ & $73 / 49 \%$ & $69 / 46.3 \%$ & \multirow{6}{*}{$10 / 10$} \\
\hline & $\mathrm{m} 2$ & 76 & $55 / 72.4 \%$ & $48 / 63.2 \%$ & $32 / 42.1 \%$ & \\
\hline & m3 & 134 & $82 / 61.2 \%$ & $70 / 52.2 \%$ & $62 / 46.3 \%$ & \\
\hline & $\mathrm{m} 4$ & 52 & $3873.1 \%$ & $35 / 67.3 \%$ & $28 / 53.8 \%$ & \\
\hline & m5 & 82 & $51 / 62.2 \%$ & $44 / 53.7 \%$ & $34 / 41.5 \%$ & \\
\hline & $\Sigma$ & 493 & $64.8 \pm 6.9 \%$ & $57.1 \pm 7 \%$ & $46 \pm 4.4 \%$ & \\
\hline \multirow{6}{*}{ Ovarian cells } & $\mathrm{m} 1$ & 79 & $55 / 69.6 \%$ & $38 / 48.1 \%$ & $32 / 40.5 \%$ & \multirow{6}{*}{$10 / 10$} \\
\hline & $\mathrm{m} 2$ & 37 & $23 / 62.2 \%$ & $21 / 56.8 \%$ & $18 / 48.6 \%$ & \\
\hline & $\mathrm{m} 3$ & 63 & $39 / 61.9 \%$ & $34 / 54 \%$ & $20 / 31.7 \%$ & \\
\hline & $\mathrm{m} 4$ & 108 & $72 / 66.7 \%$ & $68 / 63.8 \%$ & $53 / 49.1 \%$ & \\
\hline & m5 & 97 & $42 / 43.3 \%$ & $30 / 30.9 \%$ & $24 / 24.7 \%$ & \\
\hline & $\Sigma$ & 384 & $60.7 \pm 9.2 \%$ & $50.5 \pm 10.9 \%$ & $38.9 \pm 9.5 \%$ & \\
\hline \multirow{8}{*}{ Control } & $\mathrm{m} 1$ & 114 & $95 / 83.3 \%$ & $87 / 76.3 \%$ & $70 / 61.4 \%$ & \multirow{8}{*}{$10 / 10$} \\
\hline & $\mathrm{m} 2$ & 89 & $61 / 68.5 \%$ & $49 / 51.1 \%$ & $44 / 49.4 \%$ & \\
\hline & $\mathrm{m} 3$ & 74 & $52 / 70.3 \%$ & $49 / 62.2 \%$ & $43 / 58.1 \%$ & \\
\hline & $\mathrm{m} 4$ & 82 & $43 / 52.4 \%$ & $38 / 46.3 \%$ & $32 / 39 \%$ & \\
\hline & $\mathrm{m} 5$ & 34 & $28 / 82.4 \%$ & $25 / 73.5 \%$ & $22 / 64.7 \%$ & \\
\hline & $\mathrm{m} 6$ & 98 & $65 / 66.3 \%$ & $58 / 59.2 \%$ & $45 / 45.9 \%$ & \\
\hline & $\mathrm{m} 7$ & 56 & $38 / 67.9 \%$ & $32 / 57.1$ & $24 / 42.9 \%$ & \\
\hline & $\Sigma$ & 547 & $70.2 \pm 9.7 \%$ & $61.4 \pm 9.7 \%$ & $51.6 \pm 9.1 \%$ & \\
\hline
\end{tabular}

300

301

302

303

304

305

306

307

308

309

310

\section{1}

Table 4 Fertilization test of triploid germline chimeras after semi-artificial mating with $A B$ females.

Table 4 shows overall results of fertilization test when germline chimeric males previously confirmed for GFP sperm production were randomly selected (10 males from each group) and set individually with two $\mathrm{AB}$ females and allowed to spawn. Note that only successful spawnings were included in this table, while five males from TC and OC, and three males from $\mathrm{C}$ group did not induce oviposition. Fertilization rate, survival $24 \mathrm{hpf}$ and swim up rate is expressed in total numbers $/ \%$, summarized results from survival rates are expressed in $\%$ as mean \pm SD. PCR - GFP shows results of detection of GFP specific amplicon in 10 randomly selected swim up larvae from pool in each group

\section{Discussion}


312 Cold and heat shock treatments were tested in zebrafish in order to optimize method for triploid 313 production. The produced triploids were then used as sterile recipients for surrogate reproduction.

314 Heat shock treatment at $2 \mathrm{mpf}$, lasting $2 \mathrm{~min}$ with temperature $41{ }^{\circ} \mathrm{C}$ was identified as the most 315 suitable, for reliable triploid zebrafish production. All artificially induced triploids developed in 316 phenotypic sterile males. We further tested their suitability as a surrogate parents when a fraction 317 of testicular and ovarian cells was transplanted intraperitoneally. Colonization rates were in favour 318 of testicular cells, however, only male triploid germline chimeras, which were fertile and capable 319 to mate with females from AB strain, were produced.

\subsection{Triploid induction}

322 First triploid induction in zebrafish have been reported by [33], when fertilized eggs were treated at $2.5 \mathrm{mpf}$ at $41^{\circ} \mathrm{C}$, for $4 \mathrm{~min}$, however, this conditions always resulted in complete mortality in our conditions. Other studies used abovementioned protocol with slight modification such as at $2.5 \mathrm{mpf}$ at $41^{\circ} \mathrm{C}$, for $2 \mathrm{~min}$ [36] or $2 \mathrm{mpf}$ at $41^{\circ} \mathrm{C}$, for $2 \mathrm{~min}$ [37]. Our results showed, that only heat shock treatment is suitable for effective triploid production. Only partial fraction of triploid swim up larvae was obtained after optimized cold shock treatment, moreover, survival was significantly higher after HS compared to CS. All adult triploids developed in phenotypic males with testis almost free of spermatozoon, while control diploid males showed lumens filled with spermatozoon. Apparently large proportion of germ cells in triploid testis were observed to be arrested in pachytene of the first meiosis as it is result of odd chromosome number exhibiting in disorganized synapsis [38]. These results confirmed previously reported findings when all triploid zebrafish with some exception where few female individuals among males. In our study, no triploid females were detected at all. Only male occurrence in artificially induced triploid is extremely rare in fish, to the best of our knowledge documented in zebrafish [37] and Rosy bitterling [39].

\subsection{Surrogate reproduction}

Artificially induced triploids have been used successfully as recipients for surrogate gamete production in several fish species such as masu salmon [2], grass puffer [14], medaka [9], rainbow trout $[40,41]$ and nibe croaker [13]. To the best of our knowledge this study provided the first report of suitability suitability of triploid swim up larvae as a recipient for intraspecific transfer of germ cells and production of donor-derived gametes. As was previously described, triploid zebrafish developed in males only [37], even after rescuing their fertility by transplantation of testicular or ovarian cells. 
346 Germ stem cells have been proved to be bipotential gamete precursors as they can develop in 347 recipients gonads into female or male germ cells according to the recipient's sex [3]. 348 Spermatogonia transplantation in species with male heterogamety resulted in partial production of 349 YY rainbow trout supermales after mating male and female germline chimeras. This approaches 350 could serve as an alternative for mono sex culture production which is normally achieved by 351 production and subsequent mating of androgenetic or gynogenetic stocks [42].

352 Situation in zebrafish and sex control is more complicated, since some families can produce 353 extremely biased offspring when percentage of males can vary from $4.8 \%$ to $97.3 \%$ [43] or from $3540 \%$ to $75 \%$ when fish were challenged to unfavorable or affluent conditions [44]. This 355 phenomenon is attributed to polygenic sex determination with the further influence of the 356 surrounding environment [45,46], moreover, two zebrafish lines have been shown to lack sex357 linked loci [47]. Thus, a different subpopulation of zebrafish can produce progeny in very 358 fluctuating sex ratios.

359 Theoretically, part of progeny produced using sperm from triploid germline chimeras transplanted 360 by ovarian cells should after fertilization of normal eggs should yield fraction of WW super 361 females progeny, which could be interesting model for other fish species possessing female 362 heterogamety sex determination. Then in turn, induction of triploidy with of eggs obtained from 363 WW females fertilized with sperm from triploid germline chimera possessing $\mathrm{W}$ or $\mathrm{Z}$ 364 chromosome should yield fraction of WWW super female triploids, which could provide more 365 insights into sex determination in zebrafish and only triploid male occurrence.

366 Real use of zebrafish recipients in surrogate reproduction resulted in only male germ line chimera 367 production independently on used approach of zebrafish sterilization and type of germline transfer 368 such as using blastomeres, single PGCs or adult germ stem cell [15,48,49]. Production fertile 369 zebrafish female chimera seems to be not possible so far. Reason for literally absence of germline 370 chimera females is attributed to sterilization of recipient by PGCs depletion. In zebrafish, certain 371 numbers of PGCs are required to maintain the ovarian fate [17]. When taking in account that very 372 few of transplanted cells are capable to colonize the recipient's gonad, it is clear that such low 373 number of cells bellow a threshold (3-29 PGCs) cannot maintain ovarian fate. Moreover, it has 374 been shown that female germ cell presence is essential even in adulthood to maintain ovarian fate 375 and prevent sex reverse into functional male [50].

376 In conclusion to carry out whether and how to produce zebrafish germline chimeras producing 377 eggs, following possibilities have not been tested yet. 1) Hormonal treatment optimization for 378 zebrafish germline chimeras as was firstly attempted by Saito et al., (2008) on zebrafish x pearl 379 danio hybrid when 3 from 4 fish developed as females, but were not able to produce eggs. 2) 
Increasing a number of germ cells colonizing the recipient gonad might have an effect on sex differentiation in germ line chimera as was proven for a number of PGCs, since so far it was shown that only few individual cells are colonizing gonads after transplantation. 3) Cotransplantation of female germ stem cells with early oocytes could also act supportively for female sex differentiation in germline chimera, however, this method has not been tested yet. 4) Essentiality of dmrtl and amh gene for proper male development have been reported recently in zebrafish [51,52], thus DNA and RNA interfering approaches such knockdown or knock out could influence sex ratio in germline chimeras in favour of females.

\section{Conclusion}

Surrogate reproduction via germ cell transplantation into zebrafish triploid developed in this study could have potential to serve as an alternative way for zebrafish gene resource banking since it can be combined with a convenient method for spermatogonia cryopreservation by needle immersed vitrification [53]. Up to day, literally, thousands of mutants, transgenic lines and recently CRISPR/Cas9, ZFN or TALEN genetically engineered strains have been generated in zebrafish which makes gene banking of utmost importance [54-56]. Similarly, triploid males can be used as recipients to improve sperm production when originally few individuals are available for breeding or given line suffer from poor reproductive performance as was shown in medaka when the reproductive performance of an inbred strain was improved by transplantation into triploid surrogates [9]. From our experience, a number of early-stage germ cells obtained from testis originating from single adult zebrafish male is sufficient for intraperitoneal transplantation into at least 40-50 individuals. Thus taking into account that at least $23 \%$ of transplanted triploid zebrafish produced donor sperm (TC group), at least 10 fertile triploid males can be recovered using testis from a single donor. It is noteworthy to point out that triploid zebrafish germ line chimeras in our study were capable to mate with females from AB line in common spawning chamber, and their reproductive characteristics were comparable to mating with normal diploid males. Described HS protocol for triploid production is a simple method for sterile zebrafish production which does not require microinjection in embryos for delivery of compounds for gene knockdown or knock out to ensure sterilization. However, only sperm production from using PGCs depleted or hybrid recipient leaves an issue which needs to be addressed in order to produce donor derive eggs from zebrafish recipient.

Acknowledgements 
412 The study was financially supported by the Ministry of Education, Youth and Sports of the Czech 413 Republic, projects CENAKVA (LM2018099) and Biodiversity 414 (CZ.02.1.01/0.0/0.0/16_025/0007370), by the Grant Agency of the University of South Bohemia 415 in České Budějovice GAJU 097/2019/Z and 034/2017/Z. The Czech Science Foundation (project 416 No. 17-19714Y) and NAZV QK1910248.

417 Contribution and disclosure

418 RF and MP: conceptualization, designing of the study, performing experiments, data collection 419 and funding acquisition, TT: data collection and analysis, CS and MF: ploidy analysis and 420 histology sections. All authors contributed on manuscript drafting and approved the submitted 421 version.

422 Declarations of interest: none.

423 The funders had no role in study design, data collection and analysis, and preparation of the 424 manuscript. 
References

[1] de Siqueira-Silva DH, Saito T, dos Santos-Silva AP, da Silva Costa R, Psenicka M, Yasui GS. Biotechnology applied to fish reproduction: tools for conservation. Fish Physiol Biochem 2018;44:1469-85. doi:10.1007/s10695-018-0506-0.

[2] Okutsu T, Shikina S, Kanno M, Takeuchi Y, Yoshizaki G. Production of Trout Offspring from Triploid Salmon Parents. Science (80- ) 2007;317:15-7.

[3] Yoshizaki G, Lee S. Production of live fish derived from frozen germ cells via germ cell transplantation. Stem Cell Res 2018;29:103-10. doi:10.1016/J.SCR.2018.03.015.

[4] Franěk R, Tichopád T, Steinbach C, Xie X, Marinović Z, Kašpar V, et al. Preservation of female genetic resources of common carp through oogonial stem cell manipulation. Cryobiology 2019;78-85. doi:10.1016/j.cryobiol.2019.01.016.

[5] Octavera A, Yoshizaki G. Production of donor-derived offspring by allogeneic transplantation of spermatogonia in Chinese rosy bitterling. Biol Reprod 2018;0:1-10. doi:10.1093/biolre/ioy236.

[6] Farlora R, Hattori-Ihara S, Takeuchi Y, Hayashi M, Octavera A, Alimuddin, et al. Intraperitoneal germ cell transplantation in the Nile tilapia Oreochromis niloticus. Mar Biotechnol (NY) 2014;16:309-20. doi:10.1007/s10126-013-9551-y.

[7] Lacerda SMSN, Batlouni SR, Costa GMJ, Segatelli TM, Quirino BR, Queiroz BM, et al. A new and fast technique to generate offspring after germ cells transplantation in adult fish: The nile tilapia (Oreochromis niloticus) model. PLoS One 2010;5:1-9. doi:10.1371/journal.pone.0010740.

[8] Lacerda S, Batlouni S, Silva S, Homem C, França L. Germ cells transplantation in fish: the Nile-tilapia model. Anim Reprod 2006;3:146-59.

[9] Seki S, Kusano K, Lee S, Iwasaki Y, Yagisawa M, Ishida M, et al. Production of the medaka derived from vitrified whole testes by germ cell transplantation. Sci Rep 2017;7:43185. doi:10.1038/srep43185.

[10] Pšenička M, Saito T, Rodina M, Dzyuba B. Cryopreservation of early stage Siberian sturgeon Acipenser baerii germ cells, comparison of whole tissue and dissociated cells. Cryobiology 2016;72:199-122. doi:10.1016/j.cryobiol.2016.02.005. 
456

457

458

459

460

461

462

463

464

465

466

467

468

469

470

471

472

473

474

475

476

477

478

479

480

481

482

483

484

485

[11] Linhartová Z, Saito T, Kašpar V, Rodina M, Prášková E, Hagihara S, et al. Sterilization of sterlet Acipenser ruthenus by using knockdown agent, antisense morpholino oligonucleotide, against dead end gene. Theriogenology 2015;84:1246-55. doi:10.1016/j.theriogenology.2015.07.003.

[12] Ye H, Li C-J, Yue H-M, Du H, Yang X-G, Yoshino T, et al. Establishment of intraperitoneal germ cell transplantation for critically endangered Chinese sturgeon $\begin{array}{llll}\text { Acipenser } & \text { sinensis. } & \text { Theriogenology }\end{array}$ doi:10.1016/j.theriogenology.2017.02.009.

[13] Yoshikawa H, Takeuchi Y, Ino Y, Wang J, Iwata G, Kabeya N, et al. Efficient production of donor-derived gametes from triploid recipients following intra-peritoneal germ cell transplantation into a marine teleost, Nibe croaker (Nibea mitsukurii). Aquaculture 2017;478:35-47. doi:10.1016/J.AQUACULTURE.2016.05.011.

[14] Hamasaki M, Takeuchi Y, Yazawa R, Yoshikawa S, Kadomura K, Yamada T, et al. Production of Tiger Puffer Takifugu rubripes Offspring from Triploid Grass Puffer Takifugu niphobles Parents. Mar Biotechnol 2017;19:579-91. doi:10.1007/s10126-0179777-1.

[15] Li Q, Fujii W, Naito K, Yoshizaki G. Application of dead end -knockout zebrafish as recipients of germ cell transplantation. Mol Reprod Dev 2017. doi:10.1002/mrd.22870.

[16] Slanchev K, Stebler J, de la Cueva-Méndez G, Raz E. Development without germ cells: the role of the germ line in zebrafish sex differentiation. Proc Natl Acad Sci U S A 2005;102:4074-9. doi:10.1073/pnas.0407475102.

[17] Tzung KW, Goto R, Saju JM, Sreenivasan R, Saito T, Arai K, et al. Early depletion of primordial germ cells in zebrafish promotes testis formation. Stem Cell Reports 2015;4:6173. doi:10.1016/j.stemcr.2014.10.011.

[18] Wong T-T, Zohar Y. Production of reproductively sterile fish by a non-transgenic gene silencing technology. Sci Rep 2015:1-6. doi:10.1016/j.ygcen.2014.12.012.

[19] Zhou L, Feng Y, Wang F, Dong X, Jiang L, Liu C, et al. Generation of all-male-like sterile zebrafish by eliminating primordial germ cells at early development. Sci Rep 2018;8:1-12. doi:10.1038/s41598-018-20039-3.

[20] Wong TT, Collodi P. Inducible Sterilization of Zebrafish by Disruption of Primordial Germ 
Cell Migration. PLoS One 2013;8:1-8. doi:10.1371/journal.pone.0068455.

487

488

489

490

491

492

493

494

495

496

497

498

499

500

501

502

503

504

505

506

507

508

509

510

511

512

513

514

[21] Nóbrega RH, Greebe CD, van de Kant H, Bogerd J, de França LR, Schulz RW. Spermatogonial stem cell niche and spermatogonial stem cell transplantation in zebrafish. PLoS One 2010;5:1-16. doi:10.1371/journal.pone.0012808.

[22] Wong T-T, Saito T, Crodian J, Collodi P. Zebrafish germline chimeras produced by transplantation of ovarian germ cells into sterile host larvae. Biol Reprod 2011;84:1190-7. doi:10.1095/biolreprod.110.088427.

[23] Piva LH, de Siqueira-Silva DH, Goes CAG, Fujimoto T, Saito T, Dragone LV, et al. Triploid or hybrid tetra: Which is the ideal sterile host for surrogate technology? Theriogenology 2018;108:239-44. doi:10.1016/j.theriogenology.2017.12.013.

[24] Otani S, Ohara M, Miyashita S, Kobayashi T. A method for the microinjection into naturally spawned eggs of marine fish, especially cultured Pacific bluefin tuna Thunnus orientalis. Fish Sci 2008;74:208-10. doi:10.1111/j.1444-2906.2007.01512.x.

[25] Goto R, Saito T, Matsubara T, Yamaha E. Microinjection of Marine Fish Eggs. Humana Press, New York, NY; 2019, p. 475-87. doi:10.1007/978-1-4939-8831-0_27.

[26] Tiwary BK, Kirubagaran R, Ray AK. The biology of triploid fish. Rev Fish Biol Fish 2004;14:391-402. doi:10.1007/s11160-004-8361-8.

[27] Arai K. Genetic improvement of aquaculture finfish species by chromosome manipulation techniques in Japan. Aquaculture 2001;197:205-28. doi:10.1016/S0044-8486(01)00588-9.

[28] Hulata G. Genetic manipulations in aquaculture: A review of stock improvement by classical and modern technologies. Genetica 2001;111:155-73. doi:10.1023/A:1013776931796.

[29] Felip A, Zanuy S, Carrillo M, Piferrer F. Induction of triploidy and gynogenesis in teleost fish with emphasis on marine species. Genetica 2001;111:175-95. doi:10.1023/A:1013724322169.

[30] Zhou L, Gui J. Natural and artificial polyploids in aquaculture. Aquac Fish 2017;2:103-11. doi:10.1016/j.aaf.2017.04.003.

[31] Piferrer F, Beaumont A, Falguière JC, Flajšhans M, Haffray P, Colombo L. Polyploid fish and shellfish: Production, biology and applications to aquaculture for performance 
improvement and genetic containment. Aquaculture

2009;293:125-56. doi:10.1016/j.aquaculture.2009.04.036.

[32] Hassan A, Okomoda VT, Pradeep PJ. Triploidy induction by electric shock in red hybrid tilapia. Aquaculture 2018;495:823-30. doi:10.1016/J.AQUACULTURE.2018.06.074.

[33] Kavumpurath S, Pandian TJ. Induction of triploidy in the zebrafish, Brachydanio rerio (Hamilton). Aquac Res 1990;21:299-306. doi:10.1111/j.1365-2109.1990.tb00468.x.

[34] Rodina M, Cosson J, Gela D, Linhart O. Kurokura solution as immobilizing medium for spermatozoa of tench (Tinca tinca L.). Aquac Int 2004;12:119-31. doi:10.1023/B:AQUI.0000017192.75993.e3.

[35] Benjamini, Yoav., Hochberg Y. Controlling the false discovery rate a practical and powerful approach to multiple testing. J $\mathrm{R}$ Stat Soc 1995;57:289-300. doi:10.2307/2346101.

[36] Mizgireuv IV. Majorova IG, Gorodinskaya VM, Khudoley VV. Revskoy SY. Carcinogenic Effect of N-Nitrosodimethylamine on Diploid and Triploid Zebrafish (Danio rerio). Toxicol Pathol 2004;32:514-8. doi:10.1080/01926230490496311.

[37] Delomas TA, Dabrowski K. Why are triploid zebrafish all male? Mol Reprod Dev 2018;85:612-21. doi:10.1002/mrd.22998.

[38] Feitsma H, Leal MC, Moens PB, Cuppen E, Schulz RW. Mlhl deficiency in zebrafish results in male sterility and aneuploid as well as triploid progeny in females. Genetics 2007;175:1561-9. doi:10.1534/genetics.106.068171.

[39] Ueno K, Arimoto B. Induction of triploids in Rhodeus ocellatus ocellatus by cold shock treatment of fertilized eggs. Experientia 1982;38:544-6. doi:10.1007/BF02327041.

[40] Lee S, Katayama N, Yoshizaki G. Generation of juvenile rainbow trout derived from cryopreserved whole ovaries by intraperitoneal transplantation of ovarian germ cells. Biochem Biophys Res Commun 2016;478:1478-83. doi:10.1016/j.bbrc.2016.08.156.

[41] Lee S, Iwasaki Y, Shikina S, Yoshizaki G. Generation of functional eggs and sperm from cryopreserved whole testes. Proc Natl Acad Sci USA 2013;110:1640-5. doi:10.1073/pnas.1218468110.

[42] Okutsu T, Shikina S, Sakamoto T, Mochizuki M, Yoshizaki G. Successful production of 
functional $\mathrm{Y}$ eggs derived from spermatogonia transplanted into female recipients and subsequent production of YY supermales in rainbow trout, Oncorhynchus mykiss. Aquaculture 2015;446:298-302. doi:10.1016/j.aquaculture.2015.05.020.

[43] Liew WC, Bartfai R, Lim Z, Sreenivasan R, Siegfried KR, Orban L. Polygenic sex determination system in zebrafish. PLoS One 2012;7:e34397. doi:10.1371/journal.pone.0034397.

[44] Lawrence C, Ebersole JP, Kesseli R V. Rapid growth and out-crossing promote female development in zebrafish (Danio rerio). Environ Biol Fishes 2008;81:239-46. doi:10.1007/s10641-007-9195-8.

[45] Nagabhushana A, Mishra RK. Finding clues to the riddle of sex determination in zebrafish. J Biosci 2016;41:145-55.

[46] Liew WC, Orbán L. Zebrafish sex: a complicated affair. Brief Funct Genomics 2014;13:172-87. doi:10.1093/bfgp/elt041.

[47] Wilson CA, High SK, McCluskey BM, Amores A, Yan Y, Titus TA, et al. Wild sex in zebrafish: loss of the natural sex determinant in domesticated strains. Genetics 2014;198:1291-308. doi:10.1534/genetics.114.169284.

[48] Kawakami Y, Goto-Kazeto R, Saito T, Fujimoto T, Higaki S, Takahashi Y, et al. Generation of germ-line chimera zebrafish using primordial germ cells isolated from cultured blastomeres and cryopreserved embryoids. Int J Dev Biol 2010;54:1491-9. doi:10.1387/ijdb.093059yk.

[49] Saito T, Goto-Kazeto R, Arai K, Yamaha E. Xenogenesis in teleost fish through generation of germ-line chimeras by single primordial germ cell transplantation. Biol Reprod 2008;78:159-66. doi:10.1095/biolreprod.107.060038.

[50] Dranow DB, Tucker RP, Draper BW. Germ cells are required to maintain a stable sexual phenotype in adult zebrafish. Dev Biol 2013;376:43-50. doi:10.1016/J.YDBIO.2013.01.016.

[51] Webster KA, Schach U, Ordaz A, Steinfeld JS, Draper BW, Siegfried KR. Dmrt1 is necessary for male sexual development in zebrafish. Dev Biol 2017;422:33-46. doi:10.1016/j.ydbio.2016.12.008.

[52] Lin Q, Mei J, Li Z, Zhang X, Zhou L, Gui J-F. Distinct and Cooperative Roles of amh and 
dmrt1 in Self-Renewal and Differentiation of Male Germ Cells in Zebrafish. Genetics 2017;207:1007-22. doi:10.1534/genetics.117.300274.

576

577

578

579

580

581

582

583

584

585

586
[53] Marinović Z, Lujić J, Kása E, Csenki Z, Urbányi B, Horváth Á. Cryopreservation of Zebrafish Spermatogonia by Whole Testes Needle Immersed Ultra-Rapid Cooling. J Vis Exp 2018:2-7. doi:10.3791/56118.

[54] Geisler R, Köhler A, Dickmeis T, Strähle U, Strähle U, Scholz S, et al. Archiving of zebrafish lines can reduce animal experiments in biomedical research. EMBO Rep 2016;18:128-32. doi:10.15252/embr.201643561.

[55] Robles V, Cabrita E, Paz Herráez M. Germplasm Cryobanking in Zebrafish and Other Aquarium Model Species. Zebrafish 2009;6:281-93. doi:10.1089/zeb.2009.0592.

[56] Agca Y. Genome resource banking of biomedically important laboratory animals. Theriogenology 2012;78:1653-65. doi:10.1016/J.THERIOGENOLOGY.2012.08.012. 


\section{Figures}

Color should be used for all figures listed bellow.

Figure 1 Survival and success rate of triploid induction using cold shock (A-C) and heat shock treatment (D-F). D) result from treatment at $42{ }^{\circ} \mathrm{C}$ were excluded because of total mortality of treated embryos. E) Results from heat shock duration for 4 min were excluded because of total mortality of treated embryos. Different letters above the confidence intervals (survival) or SD lines (number of triploids) indicate statistical significance (Tukey's HSD, $\mathrm{p}<$ $0.05)$.

Figure 2 Donors used for germ cell transplantation into triploid surrogate recipients. Ventral view on dissected vas:EGFP donors, A) male, bright field and $\mathrm{A}^{\prime}$ ) fluorescent caption of testis, B) female, bright field and B') fluorescent caption of ovaries. Scale bars A and $\mathrm{A}^{\prime}$ $2500 \mu \mathrm{m}, \mathrm{B}$ and $\mathrm{B}^{\prime} 5000 \mu \mathrm{m}$.

Figure 3 Patterns of colonization after vas:EGFP germ cells transplantation into triploid recipients. Colonization patterns were observed 24hpf until 4wpt. Captions were taken using DA/FI/TR fluorescent filter. A-E) view on whole fish, scale bar $2 \mathrm{~mm}$. White rectangle depicts magnified view on vas:EGFP transplanted cells $A^{\prime}-E^{\prime}$, scale bars $500 \mu \mathrm{m}$.

Figure 4 Gonadal development in juvenile and adult triploid germline chimera. A-B) observation of gonadal development at 10wpt, positive colonization could be detected in vivo, B', C') - germ cell colonization is detected by GFP signal and pointed out by white arrowhead. B') ventral view on germline chimera gonads, with strong GFP signal in the right testis, left testis is non colonized (white arrow). White rectangles depict magnified captions of the colonized gonad $\left(\mathrm{B}^{\prime}, \mathrm{C}^{\prime}\right.$ and $\left.\mathrm{E}^{\prime}\right) . \mathrm{D}, \mathrm{E}^{\prime}$ ) ventral bright field and fluorescent view on 
gonads of adult triploid germline chimera. White rectangles depict magnified captions of the colonized gonad $\left(\mathrm{C}^{\prime}-\mathrm{D}^{\prime}\right)$. White arrow indicates non colonized part of testis, white arrowheads indicate colonized testis with transplanted germ cells. F, F') non transplanted triploid control. Scale bars A-B', D-D', F-F' $2500 \mu \mathrm{m}, C_{-} C^{\prime} 750 \mu \mathrm{m}, \mathrm{E}^{\prime} \mathrm{E}^{\prime} 250 \mu \mathrm{m}$.

Figure 5 Photomicrographs of histological sections of zebrafish testis. View on whole testis is in right upper corner. A) triploid individual, empty lumen is pointed out by arrow. B) diploid control male, lumen with spermatozoon is pointed out by arrow. Scale bars $50 \mu \mathrm{m}$.

Figure 6 Analysis of germline transmission in triploid surrogates. A) fluorescent photomicrograph of sperm collected from triploid zebrafish germline chimera transplanted by testicular cells. White arrowheads indicate the head of spermatozoon with positive GFP signal. B) sperm collected from control diploid AB line male. Scale bars $20 \mu \mathrm{m}$. 


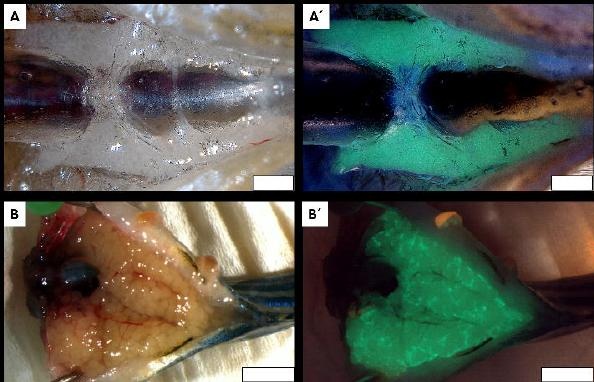



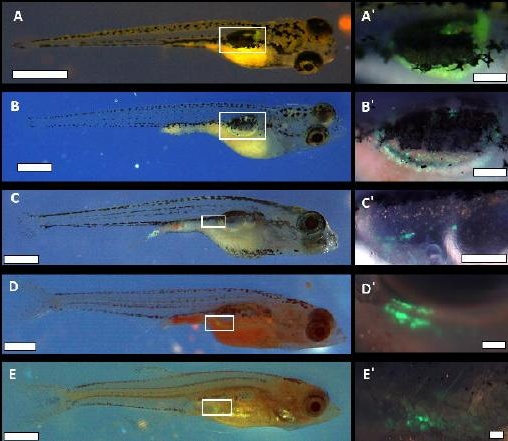

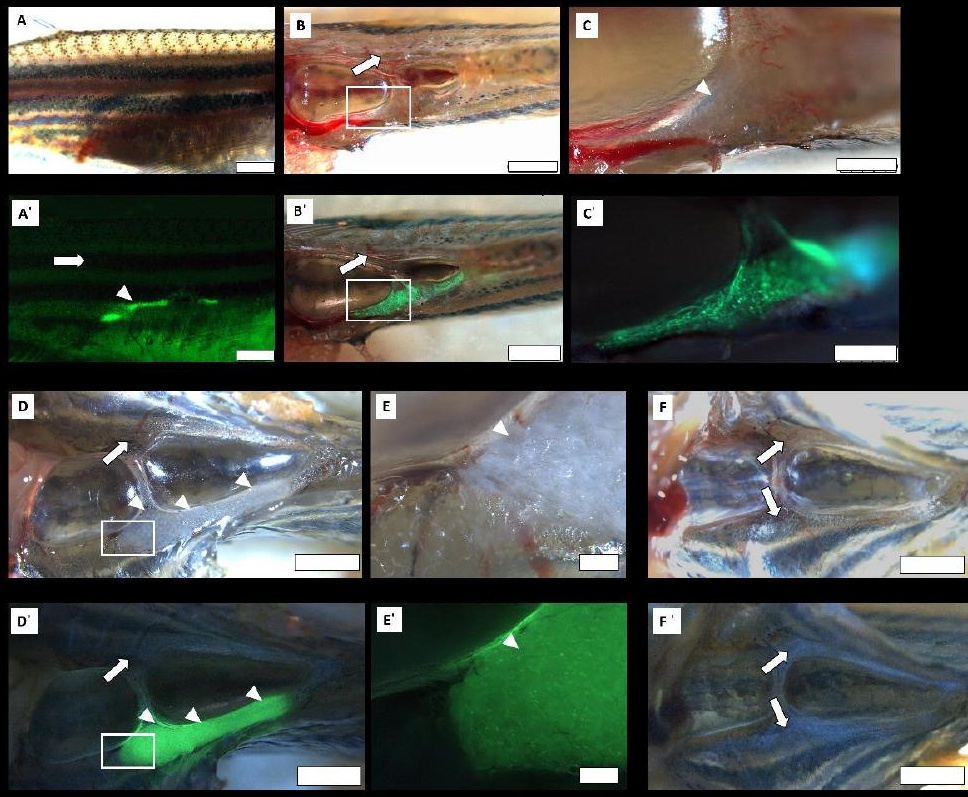


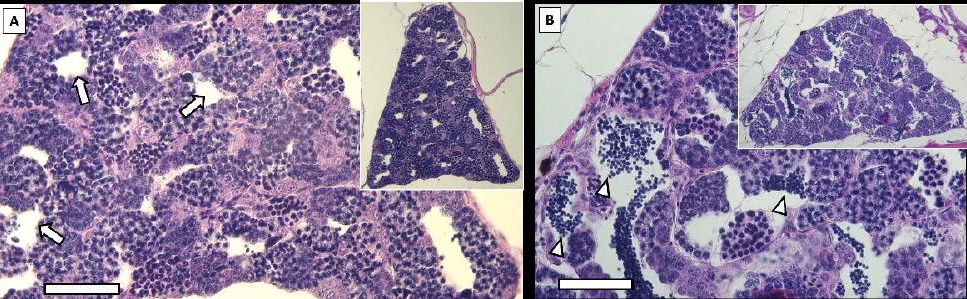


